\title{
Animal Models and Therapeutic Prospects for Charcot-Marie-Tooth Disease
}

\author{
Delphine Bouhy, PhD and Vincent Timmerman, PhD
}

\begin{abstract}
Charcot-Marie-Tooth (CMT) neuropathies are inherited neuromuscular disorders caused by a length-dependent neurodegeneration of peripheral nerves. More than 900 mutations in 60 different genes are causative of the neuropathy. Despite significant progress in therapeutic strategies, the disease remains incurable. The increasing number of genes linked to the disease, and their considerable clinical and genetic heterogeneity render the development of these strategies particularly challenging. In this context, cellular and animals models provide powerful tools. Efficient motor and sensory tests have been developed to assess the behavioral phenotype in transgenic animal models (rodent and fly). When these models reproduce a phenotype comparable to CMT, they allow therapeutic approaches and the discovery of modifiers and biomarkers. In this review, we describe the most convincing transgenic rodent and fly models of CMT and how they can lead to clinical trial. We also discuss the challenges that the research, the clinic, and the pharmaceutical industry will face in developing efficient and accessible treatment for CMT patients.
\end{abstract}

ANN NEUROL 2013;74:391-396

$\mathrm{C}^{\mathrm{n}}$ harcot-Marie-Tooth (CMT) diseases are inherited peripheral neuropathies that cause a progressive degeneration of the peripheral nerves. The degeneration follows a distal to proximal pattern and results in muscle atrophy and weakness of distal limbs associated with motor and sensory loss. The onset of the disease varies from childhood to late adulthood. CMT diseases are segregated into a demyelinated form (CMT1), the most common, characterized by a primary progressive demyelination and decreased conduction velocity of the peripheral nerve, and an axonal form (CMT2), characterized by axonal degeneration and decreased amplitudes of the nerve action potentials. ${ }^{1}$ Although these 2 main subtypes are commonly used to classify CMT, overlapping phenotypes exist, and CMT1 patients can show signs of secondary axonal degeneration. ${ }^{2}$ Among the different subtypes, patients are unequally affected by motor and sensory deficits that range from foot deformities to severe walking disabilities and wheelchair requirement.

The heterogeneity of the phenotype is further reflected by the heterogeneity of the genotype and the complexity of the phenotype/genotype correlation. ${ }^{3}$ So far, $>900$ mutations in 60 genes (partial list can be found at http://www.molgen.vib-ua.be/CMTMutations/ Home/IPN.cfm) are associated with the disease. Despite the considerable advances allowed by progress in genetic research, $75 \%$ of the causative genes are still unknown. Furthermore, the various clinical groups overlap. Mutations in a single gene can cause different phenotypes or different forms (demyelinating vs axonal), and the same phenotype can be caused by mutations in different genes. CMT remains incurable and affects approximately 1 in 2,500 people. It concerns 50,000 people in the European Union and probably $>2.6$ million worldwide. ${ }^{4,5}$

\section{Available Therapies and Therapeutic Strategies}

Although no therapy exists for CMT, supportive care has been developed to stabilize gait, to decrease the foot drop, and to relieve patients from neuropathic and mechanical pain. However, systematic analyses of the efficiency of orthotics and arthrodesis surgery on motor 
function in CMT patients are lacking or reach divergent conclusions. $^{6-8}$ Most preclinical studies concern the demyelinating form of CMT (CMT1), which is the most common. The CMT1A, CMT1B, and CMT1X subtypes represent $50 \%$ of CMT patients. Some of the genes involved in CMT1, such as PMP22, GJB1, and $M P Z$, are specifically expressed in Schwann cells and affect the myelination of the nerve.

CMT1A is caused by mutations in the PMP22 gene coding for peripheral myelin protein 22 , a transmembrane protein of Schwann cell myelin. In CMT1A patients, a duplication of 1 of the PMP22 gene alleles induces an increased expression of PMP22 mRNA. ${ }^{9}$ The addition of an extra copy of the gene in rodents has allowed convincing modeling of CMT1A, ${ }^{10-13}$ reproducing the 1.6- to 2fold increase in PMP22 mRNA and the progressive demyelination and axonal loss observed in patients. PMP22 is also subject to leucine-to-proline (L16P) and glycine-toaspartic acid (G150D) mutations. These point mutations are causative of the CMT1E subtype and represent 2.5\% of the CMT cases. These mutations occur spontaneously in Trembler (Tr) and Trembler-J (TrJ) mice, which are therefore relevant models for CMT1E. ${ }^{14-16}$ Although the pathomechanisms for CMT1E are not fully understood, the mutated protein has been shown to misfold and accumulate in Schwann cells. ${ }^{17-19}$ Based on these models, 1 of the therapeutic strategies for CMT1A and CMT1E has been to reduce the toxic effect of PMP22 overexpression. The reduction of the toxic overexpression of PMP22 with onapristone (an inhibitor of progesterone receptor) or ascorbic acid (vitamin C) has given promising results in rodent models. ${ }^{20,21}$ However, clinical studies have failed to show improvement in CMT1A patients. ${ }^{22}$ Other strategies aimed at promoting axonal regeneration with neurotrophin 3 (NT-3) or stimulating autophagy with curcumin have been successful in the $\operatorname{Tr}$ and $\operatorname{TrJ}$ mouse models. ${ }^{23,24}$ A clinical trial using NT-3 on CMT1A patients gave mitigated results, as the sensory but not the motor neuropathy score showed some improvement in treated patients. ${ }^{23}$ The divergent results between preclinical studies and clinical trials can partially be explained by inadequate conclusions from the experimental studies. In the Tr-J mice, the efficiency of curcumin was demonstrated only in newborn mice and not when the treatment was initiated in adulthood, ${ }^{24}$ which may have predicted the limited translation to clinic. In the CMT1A mice, onapristone treatment could decrease PMP22 mRNA and improve clinical phenotype, but had no effect on myelin pathology. 25

The second most common form of the disease is CMT1X caused by $>250$ mutations in the GJB1 gene coding for connexin 32 , a protein of the compact myelin. ${ }^{26}$ The similarities between patient phenotype and the phenotype developed by the mouse knockdown for Gjb1 $\left(\mathrm{Gjb} 1^{-1-}\right.$ ) or expressing the R142W mutant form of the protein suggest that the mutations induce a loss of function. ${ }^{27-31}$ Some neurological improvement is seen in $\mathrm{Gjb1}^{-/-}$mice after dampening the inflammatory reaction through downregulation of $\mathrm{T}$ cells ${ }^{32}$ or macrophages. ${ }^{33,34}$

The third most common form of CMT is associated with the myelin protein zero (MPZ or $\mathrm{P} 0$ ), the most abundant protein in peripheral myelin. More than 100 mutations in MPZ have been associated with the demyelinating or axonal form of CMT as well as other more severe forms of peripheral neuropathy such as Dejerine-Sottas syndrome or congenital hypomyelination. $^{35-37}$ The mutations result in dysfunctional mRNAs, which escape the nonsense-mediated decay and accumulate in the endoplasmic reticulum (ER) or the myelin. ${ }^{38-}$ 41 The mouse model MpzS63del mimics the distal demyelination and reduced nerve conduction velocity observed in CMT1B patients. ${ }^{41}$ This model could therefore be suitable to test the effect of ER unfolded protein response inhibition on Schwann cell survival and demyelination.

The axonal form of CMT concerns $20 \%$ of the patients $^{42}$ and has been linked to $>15$ genes. Some CMT2-related genes such as NEFL, GAN1, and KIF1B are involved in neuron-specific functions such as cytoskeleton organization or axonal transport. Many other CMT2-related genes coding for small heat shock proteins (HSPB1, HSPB3, HSPB8), aminoacyl-tRNA synthetases (GARS, YARS, AARS, HARS, KARS), and proteins involved in lipid metabolism (eg, MTMR2, RAB7, SPTLC1, SPTLC2) are ubiquitously expressed and have pleiotropic functions. These functions range from chaperone activity to autophagy, vesicular transport, or protein and lipid biosynthesis. Why mutations in these genes specifically affect the axonal compartment of motor neurons is a challenging question that waits to be solved. The 2 animal models of CMT2 that have been developed are the mutant mouse for the neurofilaments light gene NEFL, which models CMT2E, ${ }^{43}$ and the mutant mouse for the heat shock protein B1 HSPB1, which models CMT2F. ${ }^{44}$ The latter represents the first attempt of therapeutic strategy for CMT2. ${ }^{44}$ In the transgenic mouse model used in this study, the mutant forms S135F and P182L of HSPB1 depend on Thy1.2, a neuronal promoter, allowing the expression of the transgene exclusively in neurons. Remarkably, this conditional expression is sufficient to elicit a phenotype resembling CMT. At 6 months of age, mice develop a progressive decline of the motor functions and axonal degeneration, and show denervation of the neuromuscular junction and 
reduced action potential of the sciatic nerve (compound muscle action potential). ${ }^{44}$ HSPB1 belongs to the small heat shock protein family. These proteins are molecular chaperones whose canonical role involves protein folding under stress conditions, such as heat shock. ${ }^{45}$ They are ubiquitously expressed and are involved in many essential functions ranging from cytoskeleton regulation to apoptosis, autophagy, and oxidative stress. ${ }^{46-49}$ Three members of the small heat shock family have been associated with CMT: HSPB1, HSPB3, and HSPB8. ${ }^{50-52}$ The HSPB1 gene is associated with 17 CMT-causing mutations. ${ }^{50,51,53-56}$ Nine of these mutations are located in the $\alpha$-crystallin domain, which is conserved among the sHSP family and is essential for the formation of large oligomers. Mutations located inside or outside the $\alpha$ crystallin domain have different effects on the protein and result in different pathomechanisms. Only the mutations located inside the $\alpha$-crystallin domain have an increased affinity for microtubules (MTs), resulting in an overstabilized MT network. ${ }^{57,58}$ Interestingly, some cancer therapies using MT-stabilizing agents such as taxol can eventually lead to peripheral neuropathy. ${ }^{59,60}$ In the previously described mouse model of CMT2F, HSPB1 mutants also show an increased affinity for MT, resulting in their overstabilization, at a presymptomatic stage. ${ }^{58}$ Stabilized MTs are often acetylated. At a postsymptomatic stage, the MTs are deacetylated, and the acetylation can be recovered and the CMT phenotype rescued by using histone deacetylase inhibitors. These results suggest that a sustained overstabilization of the MTs activates regulatory mechanisms that eventually reverse the acetylation status of the MTs. This deacetylation would be pathogenic. ${ }^{61}$ This is so far the only attempt at therapeutic strategy and dissection of pathomechanisms for an axonal form of CMT.

There are limits and caveats to the use of rodents to model hereditary neuropathy. The first is the difficulty of obtaining a good and relevant model for the disease. This will depend on the mouse strain and its genetic background, which cannot interfere with the phenotype, and on the promoter of the transgene, which should allow moderate expression of the target protein to avoid artifacts linked to overexpression. Second, the development of such model and their phenotypic assessment is time consuming. Also, the apparition of the expected phenotype can never be guaranteed. Given the numerous mutations and genes associated with CMT, the development of a mouse model for each of them represents a laborious strategy. However, when an adequate model has been developed, it becomes a powerful tool do dissect the pathomechanisms and assess therapeutic strategies.
Another model, Drosophila melanogaster, gains increasing interest. Drosophila can be an efficient model for the discovery of new therapeutics. ${ }^{62,63}$ The complete genome of Drosophila is known, and the necessary tools for the deletion or overexpression of any Drosophila gene are available. The advantage of the fly model is the short time of the reproductive cycle and the relatively limited and costless resources needed to grow colonies. When a fly model results in a phenotype, it can be used as a readout to test modifier genes and drugs. Crossing the original mutant flies with a wide range of genes (deleted or overexpressed) allows the discovery of potential modifiers. In this context, a modifier is a gene that will suppress or decrease the phenotype of the mutant flies. Based on the modifiers, new potential drugs can be targeted and tested. The therapeutic potential and efficiency of large arrays of these chemical components will be reflected by their ability to diminish or suppress the pathological phenotype on the original mutant flies. Because methods have been developed to properly assess motor and sensory deficits in fly, the Drosophila model is relevant to study CMT. The first and only published Drosophila model of CMT concerns a dominant intermediate form of CMT (DI-CMTC), characterized by demyelination and axonal degeneration. ${ }^{64}$ DI-CMTC is caused by 3 different mutations in the YARS gene, coding for the enzyme tyrosyl-tRNA synthetase. This ubiquitous enzyme is indispensable to protein synthesis and catalyzes the aminoacetylation of tRNA with tyrosine. Specific expression of YARS mutants in Drosophila neurons induces a progressive deficit of motor function associated with specific degeneration of the associated axons, forming the giant fiber. ${ }^{64}$ A Caenorhabditis elegans model of CMT was also recently reported. ${ }^{65}$ In this model, a sporadic mutation in HARS (hars-1 Arg137Gln) was overexpressed in $\gamma$-aminobutyric acidergic (GABAergic) neurons of the nematode and resulted in gross morphological defects in commissural axons, denoted by failure to reach the dorsal nerve cord, axonal beading, defasciculation, and breaks in the visualized GABAergic dorsal nerve cord. As a consequence, the worms developed a progressive loss of motor neuron function and coordination resembling the human CMT phenotype. ${ }^{65}$ The limits of these fly and worm models reside in the biological differences between mammals and invertebrates regarding the peripheral nervous system and peripheral glial cells. ${ }^{66}$ These differences will impact the mechanisms underlying the phenotype but also the pharmacokinetic and pharmacodynamic properties of potential therapeutic agents. These differences could lead to false positives or false negatives during a drug screening. Further validation in mammals is therefore necessary. 
In addition to model-inspired therapeutics, gene therapy is another promising strategy. When the severity of the disease correlates with the level of the mutant (overexpressed, or downregulated) protein, a gene therapy compensating for the deficit or excess could be efficient. Because the symptoms in inherited peripheral neuropathies target the differentiated neuronal cell, the adenoviral vector's ability to transfer genes into differentiated postmitotic cells makes it advantageous for a gene delivery system for the nervous system. A recent preclinical study using the adeno-associated virus type 9 shows successful and extensive transgene expression in the central nervous system and in Schwann cells. ${ }^{67}$

\section{Perspectives and Challenges for Future Therapeutic Strategies}

Although the range of therapeutic strategies for CMT is expanding, the pharmaceutical industry has shown a rather limited interest in the development of treatments. ${ }^{68}$ So far, experimental studies have focused on the pathomechanisms and therapeutic strategies for single genes. Given the genetic heterogeneity of the diseases, this might be an obstacle to investment by the pharmaceutical industry. There is a need to find common mechanisms toward which converge multiple mutations and which lead to degeneration of the peripheral nerve. Some common themes easily emerge. Cytoskeleton regulation, axonal transport and trafficking, and key processes in the maintenance of the axon, such as macroautophagy, mitochondria metabolism, and regulation of the oxidative stress, may be potential targets. As an example, several CMT2-causing mutations in NEFL, GAN1, and HSPB1 genes directly or indirectly affect intermediate filaments in neurons. ${ }^{69-71}$ Interestingly, these intermediate filaments can also be affected by mutation in Schwann cells. ${ }^{72}$ Further support for common key cellular processes comes from recent evidence showing that different CMT-causing mutations alter mitochondrial dynamics and function or autophagy. ${ }^{73-80}$ Another challenge lies in the phenotypic heterogeneity among the members of the same family sharing the same mutation. This would require predicting the efficiency of the therapeutic approaches. The use of induced pluripotent stem cells derived from the fibroblast of each patient is an interesting but expensive technique that could allow some preclinical test of efficiency. To avoid costly and lifelong unnecessary treatment, a better prediction of the disease severity is also needed. The development of biomarkers will allow a more precise understanding of the pathomechanisms. Another challenge resides in the rare forms of CMT for which the development of therapeutic strategies and clinical trials may be difficult. For these rare forms, collaboration among clinicians and institutions may need to be increased to improve the accessibility to the patient data and biosamples.

\section{Conclusions}

The first CMT disease mutation (the CMT1A duplication on chromosome $17 \mathrm{p} 11.2$ ) was described in $1991 .^{81,82}$ Since then, $>900$ mutations in 60 genes have been linked to CMT neuropathy and related disorders. The large percentage of unsolved cases predicts an increasing number of discoveries of CMT-causative genes in the coming years. Paradoxically, there is a need to focus on the therapeutic approaches. This will be achieved through a better understanding of the common pathomechanisms using adequate animal models. Finally, a real improvement in the development of efficient therapies in CMT cannot occur without an efficient partnership between patients, clinical investigators, governmental institutions, and the pharmaceutical industry.

\section{Acknowledgment}

D.B. is a postdoctoral candidate supported by the European FP7 NEUROMICS project (http://rd-neuromics.eu/). Our research is supported by the University of Antwerp, Fund for Scientific Research Flanders, Medical Foundation Queen Elisabeth, Associaton Belge Contre les Maladies Neuromusculaires, Association Française Contre les Myopathies, and American Muscular Dystrophy Association.

\section{Potential Conflicts of Interest}

Nothing to report.

\section{References}

1. Barisic N, Claeys KG, Sirotkovic-Skerlev M, et al. Charcot-MarieTooth disease: a clinico-genetic confrontation. Ann Hum Genet 2008;72(pt 3):416-441.

2. Krajewski KM, Lewis RA, Fuerst DR, et al. Neurological dysfunction and axonal degeneration in Charcot-Marie-Tooth disease type $1 \mathrm{~A}$. Brain 2000;123(pt 7):1516-1527.

3. Baets J, Timmerman V. Inherited peripheral neuropathies: a myriad of genes and complex phenotypes. Brain 2011;134(pt 6): $1587-1590$

4. Reilly MM, Murphy SM, Laura M. Charcot-Marie-Tooth disease. J Peripher Nerv Syst 2011;16:1-14.

5. Emery AE. Population frequencies of inherited neuromuscular diseases-a world survey. Neuromuscul Disord 1991;1:19-29.

6. Refshauge KM, Raymond J, Nicholson G, van den Dolder PA Night splinting does not increase ankle range of motion in people with Charcot-Marie-Tooth disease: a randomised, cross-over trial. Aust J Physiother 2006;52:193-199. 
7. Wetmore RS, Drennan JC. Long-term results of triple arthrodesis in Charcot-Marie-Tooth disease. J Bone Joint Surg Am 1989;71: 417-422.

8. Saltzman CL, Fehrle MJ, Cooper RR, et al. Triple arthrodesis: twenty-five and forty-four-year average follow-up of the same patients. J Bone Joint Surg Am 1999;81:1391-1402.

9. Katona I, Wu X, Feely SM, et al. PMP22 expression in dermal nerve myelin from patients with CMT1A. Brain 2009;132(pt 7): 1734-1740.

10. Robaglia-Schlupp A, Pizant J, Norreel JC, et al. PMP22 overexpression causes dysmyelination in mice. Brain 2002;125(pt 10): 2213-2221.

11. Verhamme $\mathrm{C}$, King $\mathrm{RH}$, ten Asbroek $\mathrm{AL}$, et al. Myelin and axon pathology in a long-term study of PMP22-overexpressing mice. J Neuropathol Exp Neurol 2011;70:386-398.

12. Rautenstrauss $B$, Zechner $U$, Hameister $H$, et al. Expression pattern of the peripheral myelin protein $22 \mathrm{kDa}$ (PMP22) in neural and non-neural tissue types of adult wildtype and Trembler mice-a comparative study. J Peripher Nerv Syst 1998;3:117-124.

13. Niemann S, Sereda MW, Rossner M, et al. The "CMT rat": peripheral neuropathy and dysmyelination caused by transgenic overexpression of PMP22. Ann N Y Acad Sci 1999;883:254-261.

14. Suter $U$, Welcher AA, Ozcelik $T$, et al. Trembler mouse carries a point mutation in a myelin gene. Nature 1992;356:241-244.

15. Suter U, Moskow JJ, Welcher AA, et al. A leucine-to-proline mutation in the putative first transmembrane domain of the 22-kDa peripheral myelin protein in the trembler-J mouse. Proc Natl Acad Sci U S A 1992;89:4382-4386.

16. Madrid RE, Lofgren A, Baets J, Timmerman V. Biopsy in a patient with PMP22 exon 2 mutation recapitulates pathology of Trembler$\mathrm{J}$ mouse. Neuromuscul Disord 2013;23:345-348.

17. Naef R, Suter U. Impaired intracellular trafficking is a common disease mechanism of PMP22 point mutations in peripheral neuropathies. Neurobiol Dis 1999;6:1-14

18. Colby J, Nicholson R, Dickson KM, et al. PMP22 carrying the trembler or trembler-J mutation is intracellularly retained in myelinating Schwann cells. Neurobiol Dis 2000;7(6 pt B):561-573.

19. Tobler AR, Liu N, Mueller L, Shooter EM. Differential aggregation of the Trembler and Trembler J mutants of peripheral myelin protein 22. Proc Natl Acad Sci U S A 2002;99:483-488.

20. Sereda MW, Meyer zu Horste G, Suter U, et al. Therapeutic administration of progesterone antagonist in a model of CharcotMarie-Tooth disease (CMT-1A). Nat Med 2003;9:1533-1537.

21. Passage E, Norreel JC, Noack-Fraissignes $P$, et al. Ascorbic acid treatment corrects the phenotype of a mouse model of CharcotMarie-Tooth disease. Nat Med 2004;10:396-401.

22. Fledrich R, Stassart RM, Sereda MW. Murine therapeutic models for Charcot-Marie-Tooth (CMT) disease. Br Med Bull 2012;102: 89-113.

23. Sahenk Z, Nagaraja HN, McCracken BS, et al. NT-3 promotes nerve regeneration and sensory improvement in CMT1A mouse models and in patients. Neurology 2005;65:681-689.

24. Khajavi M, Shiga K, Wiszniewski W, et al. Oral curcumin mitigates the clinical and neuropathologic phenotype of the Trembler-J mouse: a potential therapy for inherited neuropathy. Am J Hum Genet 2007;81:438-453.

25. Meyer zu Horste G, Prukop T, Liebetanz D, et al. Antiprogesterone therapy uncouples axonal loss from demyelination in a transgenic rat model of CMT1A neuropathy. Ann Neurol 2007;61: $61-72$.

26. Fairweather N, Bell C, Cochrane $S$, et al. Mutations in the connexin 32 gene in $\mathrm{X}$-linked dominant Charcot-Marie-Tooth disease (CMTX1). Hum Mol Genet 1994;3:29-34.
27. Hahn AF, Ainsworth PJ, Naus CC, et al. Clinical and pathological observations in men lacking the gap junction protein connexin 32 Muscle Nerve Suppl 2000;9:S39-S48.

28. Dubourg O, Tardieu S, Birouk N, et al. Clinical, electrophysiological and molecular genetic characteristics of 93 patients with $\mathrm{X}$ linked Charcot-Marie-Tooth disease. Brain 2001;124(pt 10):19581967

29. Kleopa KA, Scherer SS. Molecular genetics of X-linked CharcotMarie-Tooth disease. Neuromolecular Med 2006;8:107-122.

30. Scherer SS, Xu YT, Messing A, et al. Transgenic expression of human connexin32 in myelinating Schwann cells prevents demyelination in connexin32-null mice. J Neurosci 2005;25:1550-1559.

31. Jeng LJ, Balice-Gordon RJ, Messing A, et al. The effects of a dominant connexin32 mutant in myelinating Schwann cells. Mol Cell Neurosci 2006;32:283-298.

32. Berghoff $M$, Samsam M, Muller M, et al. Neuroprotective effect of the immune system in a mouse model of severe dysmyelinating hereditary neuropathy: enhanced axonal degeneration following disruption of the RAG-1 gene. Mol Cell Neurosci 2005;28:118127.

33. Groh J, Weis J, Zieger H, et al. Colony-stimulating factor-1 mediates macrophage-related neural damage in a model for CharcotMarie-Tooth disease type 1X. Brain 2012;135(pt 1):88-104.

34. Groh J, Heinl K, Kohl B, et al. Attenuation of MCP-1/CCL2 expression ameliorates neuropathy in a mouse model for CharcotMarie-Tooth 1X. Hum Mol Genet 2010;19:3530-3543.

35. Shy ME. Peripheral neuropathies caused by mutations in the myelin protein zero. J Neurol Sci 2006;242:55-66.

36. Warner LE, Hilz MJ, Appel SH, et al. Clinical phenotypes of different MPZ (PO) mutations may include Charcot-Marie-Tooth type 1B, Dejerine-Sottas, and congenital hypomyelination. Neuron 1996; 17:451-460.

37. De Jonghe $\mathrm{P}$, Timmerman $\mathrm{V}$, Ceuterick $\mathrm{C}$, et al. The Thr124Met mutation in the peripheral myelin protein zero (MPZ) gene is associated with a clinically distinct Charcot-Marie-Tooth phenotype. Brain 1999;122(pt 2):281-290.

38. Inoue K, Khajavi M, Ohyama $\mathrm{T}$, et al. Molecular mechanism for distinct neurological phenotypes conveyed by allelic truncating mutations. Nat Genet 2004;36:361-369.

39. Khajavi M, Inoue K, Wiszniewski W, et al. Curcumin treatment abrogates endoplasmic reticulum retention and aggregationinduced apoptosis associated with neuropathy-causing myelin protein zero-truncating mutants. Am J Hum Genet 2005;77:841850.

40. Kulkens T, Bolhuis PA, Wolterman RA, et al. Deletion of the serine 34 codon from the major peripheral myelin protein P0 gene in Charcot-Marie-Tooth disease type 1B. Nat Genet 1993;5:35-39.

41. Wrabetz $L$, D'Antonio $M$, Pennuto $M$, et al. Different intracellular pathomechanisms produce diverse myelin protein zero neuropathies in transgenic mice. J Neurosci 2006;26:2358-2368.

42. Ajroud-Driss S, Deng HX, Siddique T. Recent advances in the genetics of hereditary axonal sensory-motor neuropathies type 2 . Curr Neurol Neurosci Rep 2011;11:262-273.

43. Lee MK, Marszalek JR, Cleveland DW. A mutant neurofilament subunit causes massive, selective motor neuron death: implications for the pathogenesis of human motor neuron disease. Neuron 1994;13:975-988.

44. d'Ydewalle C, Krishnan J, Chiheb DM, et al. HDAC6 inhibitors reverse axonal loss in a mouse model of mutant HSPB1-induced Charcot-Marie-Tooth disease. Nat Med 2011;17:968-974.

45. Garrido C, Paul C, Seigneuric R, Kampinga HH. The small heat shock proteins family: the long forgotten chaperones. Int J Biochem Cell Biol 2012;44:1588-1592. 
46. Boncoraglio A, Minoia M, Carra S. The family of mammalian small heat shock proteins (HSPBs): implications in protein deposit diseases and motor neuropathies. Int J Biochem Cell Biol 2012;44: 1657-1669

47. Acunzo J, Katsogiannou M, Rocchi P. Small heat shock proteins HSP27 (HspB1), alphaB-crystallin (HspB5) and HSP22 (HspB8) as regulators of cell death. Int J Biochem Cell Biol 2012;44:1622-1631.

48. Wettstein G, Bellaye PS, Micheau O, Bonniaud P. Small heat shock proteins and the cytoskeleton: an essential interplay for cell integrity? Int J Biochem Cell Biol 2012;44:1680-1686.

49. Christians ES, Ishiwata T, Benjamin IJ. Small heat shock proteins in redox metabolism: implications for cardiovascular diseases. Int J Biochem Cell Biol 2012;44:1632-1645.

50. Irobi J, Van Impe K, Seeman $P$, et al. Hot-spot residue in small heat-shock protein 22 causes distal motor neuropathy. Nat Genet 2004;36:597-601.

51. Evgrafov OV, Mersiyanova I, Irobi J, et al. Mutant small heatshock protein 27 causes axonal Charcot-Marie-Tooth disease and distal hereditary motor neuropathy. Nat Genet 2004;36:602-606.

52. Kolb SJ, Snyder PJ, Poi EJ, et al. Mutant small heat shock protein B3 causes motor neuropathy: utility of a candidate gene approach. Neurology 2010;74:502-506.

53. Mandich P, Grandis M, Varese A, et al. Severe neuropathy after diphtheria-tetanus-pertussis vaccination in a child carrying a novel frame-shift mutation in the small heat-shock protein 27 gene. J Child Neurol 2010:25:107-109.

54. Holmgren A, Bouhy D, Timmerman V. Molecular biology of small heat shock proteins associated with peripheral neuropathies. eLS 2012; [doi: 10.1002/9780470015902.a0024294]

55. Capponi S, Geroldi A, Fossa P, et al. HSPB1 and HSPB8 in inherited neuropathies: study of an Italian cohort of dHMN and CMT2 patients. J Peripher Nerv Syst 2011;16:287-294.

56. Houlden H, Laura M, Wavrant-De Vrieze F, et al. Mutations in the HSP27 (HSPB1) gene cause dominant, recessive, and sporadic distal HMN/CMT type 2. Neurology 2008;71:1660-1668.

57. Almeida-Souza L, Goethals S, de Winter V, et al. Increased monomerization of mutant HSPB1 leads to protein hyperactivity in Charcot-Marie-Tooth neuropathy. J Biol Chem 2010;285:1277812786.

58. Almeida-Souza L, Asselbergh B, d'Ydewalle C, et al. Small heatshock protein HSPB1 mutants stabilize microtubules in CharcotMarie-Tooth neuropathy. J Neurosci 2011;31:15320-15328.

59. Wolf S, Barton D, Kottschade L, et al. Chemotherapy-induced peripheral neuropathy: prevention and treatment strategies. Eur J Cancer 2008;44:1507-1515.

60. Lee JJ, Swain SM. Peripheral neuropathy induced by microtubulestabilizing agents. J Clin Oncol 2006;24:1633-1642.

61. Almeida-Souza L, Timmerman V, Janssens S. Microtubule dynamics in the peripheral nervous system: a matter of balance. Bioarchitecture $2011 ; 1: 267-270$.

62. Sofola $O A$, Jin $P$, Qin $Y$, et al. RNA-binding proteins hnRNP $A 2 / B 1$ and CUGBP1 suppress fragile X CGG premutation repeatinduced neurodegeneration in a Drosophila model of FXTAS. Neuron 2007;55:565-571.

63. Pandey UB, Nichols CD. Human disease models in Drosophila melanogaster and the role of the fly in therapeutic drug discovery. Pharmacol Rev 2011;63:411-436.

64. Storkebaum E, Leitao-Goncalves R, Godenschwege T, et al. Dominant mutations in the tyrosyl-tRNA synthetase gene recapitulate in
Drosophila features of human Charcot-Marie-Tooth neuropathy Proc Natl Acad Sci U S A 2009;106:11782-11787.

65. Vester A, Velez-Ruiz G, McLaughlin HM, et al. A loss-of-function variant in the human histidyl-tRNA synthetase (HARS) gene is neurotoxic in vivo. Hum Mutat 2013;34:191-199.

66. Freeman MR, Doherty J. Glial cell biology in Drosophila and vertebrates. Trends Neurosci 2006;29:82-90.

67. Bevan AK, Duque S, Foust KD, et al. Systemic gene delivery in large species for targeting spinal cord, brain, and peripheral tissues for pediatric disorders. Mol Ther 2011;19:1971-1980.

68. Herrmann DN. Experimental therapeutics in hereditary neuropathies: the past, the present, and the future. Neurotherapeutics 2008;5:507-515.

69. Mahammad S, Murthy SN, Didonna A, et al. Giant axonal neuropathy-associated gigaxonin mutations impair intermediate filament protein degradation. J Clin Invest 2013;123:1964-1975.

70. Holmgren A, Bouhy D, De Winter V, et al. Charcot-Marie-Tooth causing HSPB1 mutations increase Cdk5-mediated phosphorylation of neurofilaments. Acta Neuropathol 2013;126:93-108.

71. Fabrizi GM, Cavallaro T, Angiari $C$, et al. Charcot-Marie-Tooth disease type 2E, a disorder of the cytoskeleton. Brain 2007;130(pt 2): 394-403.

72. de Waegh SM, Lee VM, Brady ST. Local modulation of neurofilament phosphorylation, axonal caliber, and slow axonal transport by myelinating Schwann cells. Cell 1992;68:451-463.

73. Lee SM, Olzmann JA, Chin LS, Li L. Mutations associated with Charcot-Marie-Tooth disease cause SIMPLE protein mislocalization and degradation by the proteasome and aggresome-autophagy pathways. J Cell Sci 2011;124(pt 19):3319-3331.

74. Kwok AS, Phadwal K, Turner BJ, et al. HspB8 mutation causing hereditary distal motor neuropathy impairs lysosomal delivery of autophagosomes. J Neurochem 2011;119:1155-1161.

75. Durieux AC, Vassilopoulos S, Laine J, et al. A centronuclear myopathy-dynamin 2 mutation impairs autophagy in mice. Traffic 2012;13:869-879.

76. Gentil BJ, Minotti $S$, Beange $M$, et al. Normal role of the lowmolecular-weight neurofilament protein in mitochondrial dynamics and disruption in Charcot-Marie-Tooth disease. FASEB J 2012;26: 1194-1203.

77. Noack R, Frede S, Albrecht P, et al. Charcot-Marie-Tooth disease CMT4A: GDAP1 increases cellular glutathione and the mitochondrial membrane potential. Hum Mol Genet 2012;21:150-162.

78. Misko A, Jiang S, Wegorzewska I, et al. Mitofusin 2 is necessary for transport of axonal mitochondria and interacts with the Miro/Milton complex. J Neurosci 2010;30:4232-4240.

79. Pedrola L, Espert A, Wu X, et al. GDAP1, the protein causing Charcot-Marie-Tooth disease type 4A, is expressed in neurons and is associated with mitochondria. Hum Mol Genet 2005;14 1087-1094.

80. Pla-Martin D, Rueda CB, Estela A, et al. Silencing of the CharcotMarie-Tooth disease-associated gene GDAP1 induces abnorma mitochondrial distribution and affects $\mathrm{Ca}$ homeostasis by reducing store-operated Ca entry. Neurobiol Dis 2013;55:140-151.

81. Lupski JR, de Oca-Luna RM, Slaugenhaupt S, et al. DNA duplication associated with Charcot-Marie-Tooth disease type 1A. Cell $1991 ; 66: 219-232$.

82. Raeymaekers $\mathrm{P}$, Timmerman $\mathrm{V}$, Nelis $\mathrm{E}$, et al. Duplication in chromosome 17p11.2 in Charcot-Marie-Tooth neuropathy type 1a (CMT 1a).The HMSN Collaborative Research Group. Neuromuscul Disord 1991;1:93-97. 